Cite this: Dalton Trans., 2013, 42, 13809

Received 13th June 2013,

Accepted 9th August 2013

DOI: $10.1039 / c 3 d t 51569 a$

\section{Sumanenylferrocenes and their solid state self-assemblyt}

\author{
Berit Topolinski, ${ }^{a, b}$ Bernd M. Schmidt, ${ }^{a, b}$ Shuhei Higashibayashi, ${ }^{b}$ Hidehiro Sakurai ${ }^{\text {b }}$ \\ and Dieter Lentz ${ }^{* a}$
}

www.rsc.org/dalton

The first ferrocene-fused organometallic compounds derived from the buckybowl sumanene $\left(\mathrm{C}_{21} \mathrm{H}_{12}\right)$ are presented. Both compounds, sumanenylferrocene and 1,1'-disumanenylferrocene, have been synthesized by Negishi-type cross-coupling of iodosumanene and were studied crystallographically. Sumanenylferrocenes form unique packing motifs, which are both different from those of their corannulene congeners and sumanene itself.

The molecular bowl sumanene $\left(\mathrm{C}_{21} \mathrm{H}_{12}\right)$ was synthesized for the first time by solution-phase methods in $2003^{1}$ and further $C_{3}$ symmetric functionalized sumanenes were reported in recent years. ${ }^{2}$ Studies on heterosumanenes followed ${ }^{3}$ and in 2012, the first nitrogen-doped, chiral triazasumanene was obtained, ${ }^{4}$ giving the possibility of a diversified use of buckybowls in coordination chemistry.

Sumanene features a slightly larger surface area than the well-studied corannulene $\left(\mathrm{C}_{20} \mathrm{H}_{10}\right)^{5}$ and a deeper bowl $(1.11 \AA$ for sumanene vs. $0.87 \AA$ for corannulene), ${ }^{6}$ which is able to coordinate a cyclopentadienyliron unit in its concave cavity resulting in the first endo-bound buckybowl complex ${ }^{7}$ and later, the first chiral complex of a $\pi$-bowl ligand. ${ }^{8}$ If the cyclopentadienyliron unit is exchanged for the corresponding ruthenium analogue, a dynamic bowl-to-bowl inversion behaviour is observed, most likely originating from the elongated carbon-ruthenium bonds. ${ }^{9}$

Compounds containing organometallic units, like ferrocenyl, connected to sumanene have not yet been prepared. It is of great interest to synthesize such assemblies employing the buckybowl sumanene, especially with respect to the highly ordered columnar structure of unsubstituted sumanene in the solid state. ${ }^{6 a}$

\footnotetext{
${ }^{a}$ Freie Universität Berlin, Fabeckstrasse 34-36, D-14195, Berlin, Germany. E-mail:dlentz@zedat.fu-berlin.de; Fax: +49-30-838-52590; Tel: +49-30-838-52695 ${ }^{b}$ Institute for Molecular Science, Myodaiji, 444-8787 Okazaki, Japan. Fax: +81 564595527; Tel: +81564595525

†Electronic supplementary information (ESI) available: Detailed synthetic procedures and characterization of compounds 2-3, as well as electrochemical data and computational details. CCDC 944834 and 944835. For ESI and crystallographic data in CIF or other electronic format see DOI: 10.1039/c3dt51569a
}

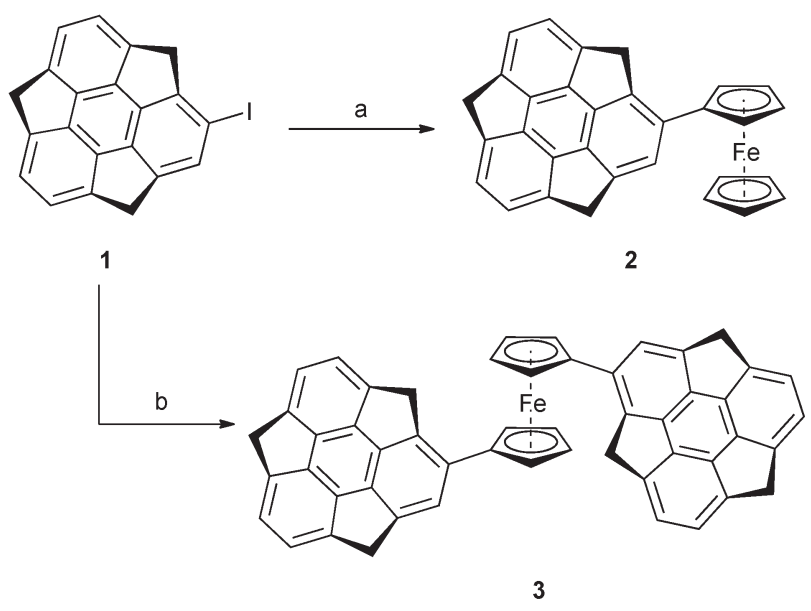

Scheme 1 Synthesis of sumanenylferrocenes: (a) 4 eq. ferrocenyl zinc chloride, 3 mol\% palladium(॥) acetate, $6 \mathrm{~mol} \%$ triphenylphosphine, THF, $70{ }^{\circ} \mathrm{C}, 3$ days; (b) 0.5 eq. 1,1'-bis(chlorozincio)ferrocene, $2.5 \mathrm{~mol} \%$ palladium(॥) acetate, $5 \mathrm{~mol} \%$ triphenylphosphine, $\mathrm{THF}, 70^{\circ} \mathrm{C}, 24 \mathrm{~h}$.

Recently, we have presented investigations regarding the intermolecular self-assembly of corannulenylferrocenes. ${ }^{10} \mathrm{~A}$ strikingly different solid state structure was found for corannulenylferrocene in contrast to 1,1'-dicorannulenylferrocene (Scheme 1). The latter forms a organometallic supramolecular nanowire-like structure by unique inter- and intramolecular slipped stacking interactions, although pristine corannulene crystallizes without any columnar order. ${ }^{11}$ Other groups investigated similar systems as well, a cyclopalladated complex of corannulene with a 2-pyridyl pendant showed not only different metal binding modes but also intriguing self-assembly behaviours in both solid state and solution. ${ }^{12}$

Starting from sumanene, monoiodosumanene $\mathrm{e}^{13 a}$ (1) can be prepared by a gold-catalysed reaction with $N$-iodosuccinimide $^{13 b}$ in $75 \%$ yield. Ferrocene is lithiated in the presence of potassium tert-butoxide and subsequently zincated for in situ Negishi-coupling with 1. Sumanenylferrocene (2) can be isolated after column chromatography on silica gel in $38 \%$ yield and is stable towards air and moisture. 1,1'- 

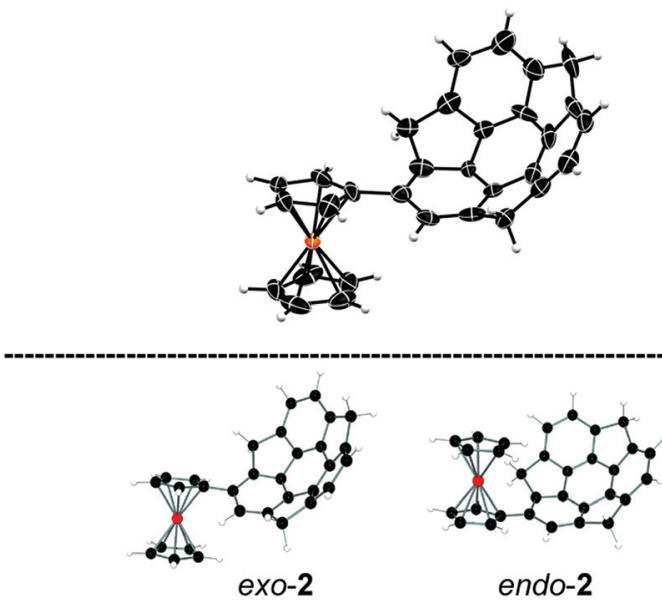

Fig. 1 Above: X-ray structure of $\mathbf{2}$ as represented by the asymmetric unit. Ellipsoids drawn at $50 \%$ probability. Mercury representation, ${ }^{14}$ rendered with POV-Ray. ${ }^{15}$ Below: calculated endo and exo conformers shown for comparison, Ortep representation. If the stereochemical descriptor proposed for buckybowls ${ }^{2 b}$ is applied (C)-2 is observed in the solid state.

Disumanenylferrocene (3) was synthesized using 1,1'-dibromoferrocene which was found to be a convenient precursor to generate 1,1'-bis(chlorozincio)ferrocene after lithiation with $n$-butyllithium and subsequent zincation, circumventing the use of TMEDA. ${ }^{10}$

The isolated yield of $11 \%$ is comparatively low, even when considering the high sensitivity of unstabilized 1,1'-dilithioferrocene and might be also attributed to the very poor solubility of $\mathbf{3}$ in common organic solvents. No other compound bearing two sumanene units was present in the reaction mixture of 3; however, significant amounts of 2 and starting materials were isolated as well. Both compounds 2 and 3 , $\neq$ are deep orange solids.

The structure of 2 was determined by single-crystal X-ray crystallography and can be solved in the monoclinic space group $P 2_{1} / c$ with one molecule in the asymmetric unit. The attached ferrocene is in exo conformation with respect to the buckybowl sumanene (Fig. 1). In contrast to the structure of 2, the direct corannulene congener bears the ferrocenyl substituent in endo conformation, as observed in the X-ray structure. ${ }^{10}$ The bowl depth of 2 remains almost unchanged upon the introduction of the ferrocenyl group to the rim of the molecule and was calculated to be approx. $1.16 \AA$ from the X-ray data.

Considering the perfect columnar solid state packing structure of sumanene, ${ }^{6 a}$ either only a slight change due to the bulky substituent might be expected or a structure similar to that of corannulenylferrocene. ${ }^{13 b}$ The latter being the case, a unit cell dominated by intermolecular $\mathrm{C}-\mathrm{H} \cdots \pi$ interactions ${ }^{16}$ is observed. Significant interactions include, but are not limited to: the $3.11 \AA$ contact of the endo hydrogen atoms of the benzylic carbons to the center of a six-membered ring above (the six membered rings of sumanene feature a more negative electrostatic potential and thus support this observation), ${ }^{6 b}$ the even shorter contact $(2.90 \AA)$ of the corresponding exo hydrogen atom to a six-membered ring of a molecule pointing

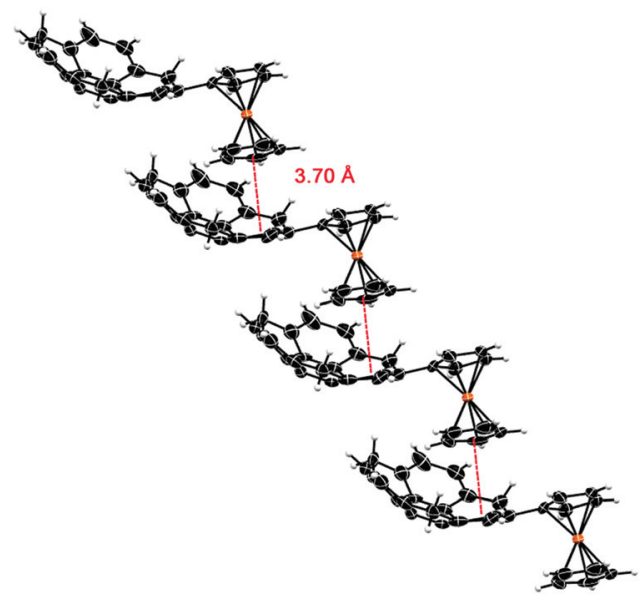

Fig. 2 The "ferrocene-in-bowl" stacking of $\mathbf{2}$ along the crystallographic a axis. $\pi \cdots \pi$ contacts are highlighted in red.

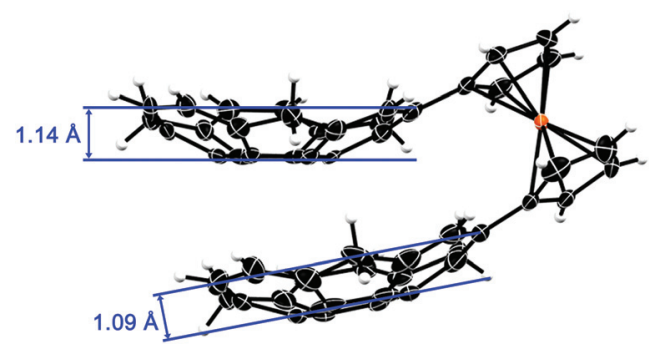

Fig. 3 The structure of $\mathbf{3}$ as represented by the asymmetric unit, with ellipsoids drawn at $50 \%$ probability. The sumanene bowls are in eclipsed conformation, like the cyclopentadienyl rings of the ferrocene. The tilt angle between the two planes of the cyclopentadienyl rings is $3.9(2)^{\circ}$, which surprisingly does not differ from $3.9(3)^{\circ}$ for 2 . The depicted molecule (asymmetric unit) corresponds to $(A, A)-3$. Due to the centrosymmetric space group $P 2_{1} / n$ the enantiomer $(C, C)-3$ is also present in the unit cell (see Fig. 5).

downward (convex bowl) and the fairly short contact $(2.53 \AA)$ of one hydrogen of the ferrocene pointing to the bowl of an adjacent molecule (Fig. S6†). Whereas no $\pi$-stacking can be observed between the molecular bowls, a unprecedented staircase like arrangement is formed between identical enantiomers in the structure by the approach of the unsubstituted five-membered cyclopentadienyl ring to the open face of the next buckybowl along the crystallographic $a$-axis $\left(\begin{array}{ll}3.70 \AA\end{array}\right)$ (Fig. 2).

The molecular structure of $\mathbf{3}$, as represented by the asymmetric unit, is shown in Fig. 3. The bowls are in concaveconvex alignment, essentially in an eclipsed fashion. A slipped stacking is observed, because the bowls are not perfectly aligned (an angle of $12.5^{\circ}$ is observed between the planes of the central six-membered rings (Fig. 3)). Calculations of sumanene dimers suggest that a staggered conformation is favoured over the eclipsed because it facilitates $\mathrm{C}-\mathrm{H} \cdots \pi$ contacts between the benzylic hydrogen atoms and the six-membered ring. ${ }^{2 d, 17}$ Whereas the bowl depth of the upper molecule remains almost unchanged (1.14 $\AA$ ), the lower molecular bowl is flattened $(1.09 \AA)$. 


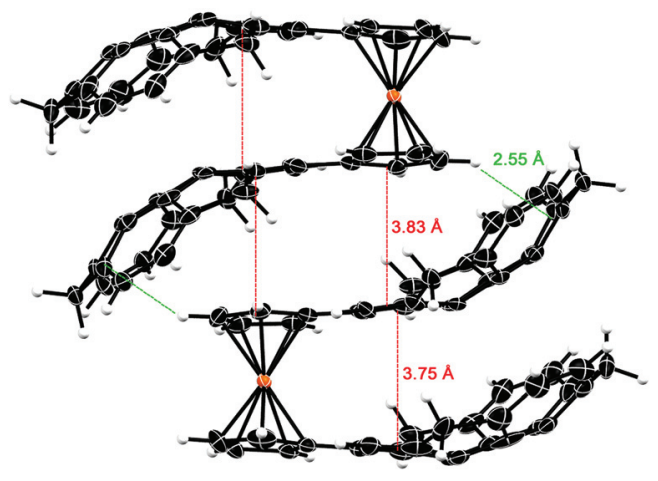

Fig. 4 Orientations of $\mathbf{3}$ in the solid state, depicted as the formation of a headto-tail dimer. $\mathrm{CH} \cdots \pi$ contacts are displayed in green, $\pi \cdots \pi$ contacts in red.

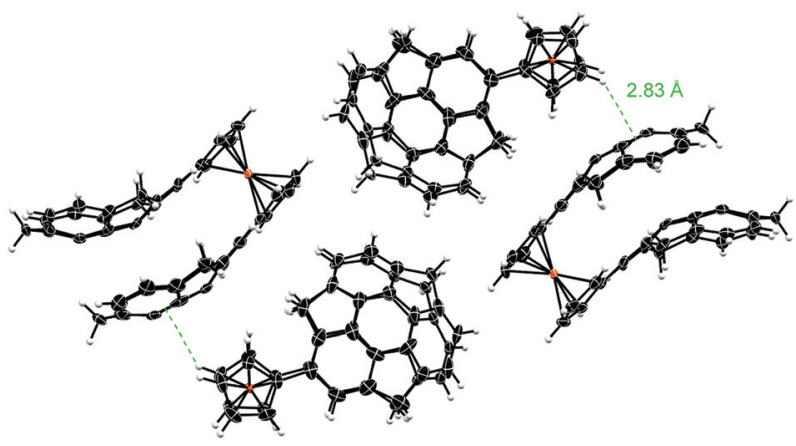

Fig. 5 A part of the unit cell of $\mathbf{3}$, see ESI (Fig. S7 and S8t) for additional representations.

Upon introduction of a second sumanene substituent to the system, the solid-state structure changes drastically. It is best described in two parts: the formation of a dimer and the interactions of the dimers with each other, for reasons of clarity and comprehensibility.

Within a dimeric unit (Fig. 4), a head-to-tail alignment is observed where the staggered bowls are hosting the ferrocene unit of its counterpart. This ligand-to-bowl $\pi$-stacking occurs at a distance of $3.83 \AA$ and is supported by a short $\mathrm{C}-\mathrm{H} \cdots \pi$ contact from the inbound cyclopentadienyl ring of only $2.55 \AA$ to the center of a five-membered ring.

The dimeric units, being perpendicular to each other (Fig. 5), give rise to the possibility of $\mathrm{C}-\mathrm{H} \cdots \pi$ interactions from a ferrocene to the outside of a close-by bowl within short distances of up to $2.83 \AA$. These are considered to be highly favorable interactions due to the negative electrostatic potential at the outside of the molecular bowl. ${ }^{16 a}$

In addition to the crystal data obtained, gas-phase DFT calculations of both structures were pursued using the $\omega$ B97XD functional on a $6-31 G(d, p)$ level. The $\omega$ B97XD calculations predict geometric parameters like the bowl depth precisely. In two of the three cases, the bowl depth of sumanene is deepened upon the introduction of ferrocene, which is also supported by the calculations. The lower bowl of $\mathbf{3}$ is always slightly flattened. In 2 and 3, the HOMO and LUMO are well distributed over the whole molecule (see ESI Fig. S9-S12†). Regarding the conformation of 2 , both the endo and the exo structure were additionally calculated by gas-phase DFT and suggest that the endo conformation is by $2.5 \mathrm{kcal} \mathrm{mol}^{-1}$ lower in energy than the exo conformation, which is present in the solid state. The bowl depth of the exo conformer is accordingly slightly flattened (1.15 vs. $1.16 \AA$ ) suffering from more sterical strain. The difference in energy is very small, therefore packing effects can easily account for the change of conformation.

Of compound 3 exist two diastereomers $(A, A)-3 /(C, C)-3$ and $(A, C)-3 /(C, A)-3$ which can be interconverted by bowl inversion and conformational changes. Thus 3 is a fluxional molecule with different activation parameters for these processes. The ${ }^{1} \mathrm{H}-\mathrm{NMR}$ of 3 is difficult to analyse due to the very poor solubility and overlapping broad signals of the ferrocene moiety and the benzylic protons of sumanene. The broadened signals in the ${ }^{1} \mathrm{H}$-NMR suggest a dynamic stereochemistry in solution where the in-plane rotation of the cyclopentadienyl ligand of the ferrocenyl moiety, bowl-inversion and rotation of the bowls occur. A similar phenomenon was extensively studied for example for bicorannulenyl by the group of Scott. ${ }^{18}$

Cyclic voltammetry measurements of 2 and 3 in THF were conducted with decamethylferrocene as an internal standard and are referenced against the ferrocene/ferrocenium couple for better comparison. A reversible oxidation on the ferrocene unit of $2\left(E_{0}=-0.03 \mathrm{~V}\right.$ referenced $v s$. ferrocene) followed by two irreversible reductions $(-3.02,-3.35 \mathrm{~V})$ was observed. The redox-potential of the ferrocene unit of $\mathbf{3}$ was found to be $-0.05 \mathrm{~V}$. Due to the very low solubility of 3 interpretations with respect to reversibility are not possible. Again irreversible processes in the cathodic region can be observed (see ESI Fig S3†).

In summary, the first ferrocene-bound sumanenes were synthesized and discussed with respect to their unforeseen crystal packings. The structures obtained are different from the parent sumanene molecule as well as their corannulene counterparts, highlighting the challenges in crystal engineering of complex molecules. Computational studies support the obtained data.

Support from the DFG, MEXT and JST (ACT-C) is gratefully acknowledged. We thank Ms. Sachiko Nakano (IMS) for technical support and Dr Beatrice Braun (HU Berlin) for the X-ray data collection of 3 .

\section{Notes and references}

$\ddagger$ Crystal data for 2 : an orange platelet crystal, $0.20 \times 0.10 \times 0.01 \mathrm{~mm}^{3}$, was mounted on the top of a glass fibre. Data were collected usinga Rigaku diffractometer with a rotating anode $(\mathrm{MoK} \alpha, 0.71073 \AA)$ at $123 \mathrm{~K}$. The structure was solved using direct methods (SHELXS-97) ${ }^{19}$ and refined by least squares methods using SHELX-97. ${ }^{19} \mathrm{C}_{31} \mathrm{H}_{20} \mathrm{Fe}, M=448.32$, monoclinic, $a=7.624(3) \AA$, $b=27.809(8) \AA, c=9.570(3) \AA, \alpha=90.000(0)^{\circ}, \beta=102.692(4)^{\circ}, \gamma=90.000(0)^{\circ}, V=$ 1979.4(17) $\AA^{3}, T=123(2) \mathrm{K}$, space group $P 2_{1} / c, Z=4,15241$ reflections measured, 4445 independent reflections $\left(R_{\mathrm{int}}=0.0377\right)$. The final $R_{1}$ values were $0.0947(I>$ $2 \sigma(I))$. The final $\mathrm{w} R\left(F^{2}\right)$ values were $0.1870(I>2 \sigma(I))$. The final $R_{1}$ values were 0.1137 (all data). The final $\mathrm{w} R\left(F^{2}\right)$ values were 0.2094 (all data). The goodness of fit on $F^{2}$ was 1.127. Crystal data for 3: an orange platelet crystal, $0.20 \times 0.15 \times$ $0.05 \mathrm{~mm}^{3}$, was mounted on the top of a glass fibre. Data were collected using a 
Bruker-AXS diffractometer with a micro focus sealed tube (MoK $\alpha, 0.71073 \AA)$ at $100 \mathrm{~K}$. The structure was solved using direct methods (SHELXS-97) ${ }^{19}$ and refined by least squares methods using SHELX-97. ${ }^{19} \mathrm{C}_{52} \mathrm{H}_{30} \mathrm{Fe}, M=710.61$, monoclinic, $a=15.7594(8) \AA, b=11.2328(5) \AA, c=18.3713(9) \AA, \alpha=90.00^{\circ}, \beta=105.643(2)^{\circ}$, $\gamma=90.00^{\circ}, V=3131.7(3) \AA^{3}, T=100(2) \mathrm{K}$, space group $P 2_{1} / n, Z=4,63873$ reflections measured, 6412 independent reflections $\left(R_{\text {int }}=0.0645\right)$. The final $R_{1}$ values were $0.0721(I>2 \sigma(I))$. The final $\mathrm{w} R\left(F^{2}\right)$ values were $0.1677(I>2 \sigma(I))$. The final $R_{1}$ values were 0.0890 (all data). The final $\mathrm{w} R\left(F^{2}\right)$ values were 0.1795 (all data). The goodness of fit on $F^{2}$ was 1.040 .

1 H. Sakurai, T. Daiko and T. Hirao, Science, 2003, 301, 1878.

2 (a) S. Higashibayashi and H. Sakurai, Chem. Lett., 2011, 122-128; (b) T. Amaya and T. Hirao, Chem. Commun., 2011, 47, 10524-10535; (c) B. M. Schmidt, B. Topolinski, S. Higashibayashi, T. Kojima, M. Kawano, D. Lentz and H. Sakurai, Chem.-Eur. J., 2013, 19, 3282-3286; (d) S. Higashibayashi, R. Tsuruoka, Y. Soujanya, U. Purushotham, G. N. Sastry, S. Seki, T. Ishikawa, S. Toyota and H. Sakurai, Bull. Chem. Soc. Jpn., 2012, 85, 450-467; (e) S. Higashibayashi, R. B. Nasir Baig, Y. Morita and H. Sakurai, Chem. Lett., 2012, 84-86; (f) T. Amaya, M. Hifumi, M. Okada, Y. Shimizu, T. Moriuchi, K. Segawa, Y. Ando and T. Hirao, J. Org. Chem., 2011, 76, 8049-8052; (g) R. Tsuruoka, S. Higashibayashi, T. Ishikawa, S. Toyota and H. Sakurai, Chem. Lett., 2010, 646-647; (h) S. Higashibayashi and H. Sakurai, J. Am. Chem. Soc., 2008, 130, 8592-8593; (i) K. Imamura, K. Takamiya, Y. Aso and T. Otsubo, Chem. Commun., 1999, 1859.

3 (a) T. Tanikawa, M. Saito, J. D. Guo, S. Nagase and M. Minoura, Eur. J. Org. Chem., 2012, 7135-7142; (b) T. Tanikawa, M. Saito, J. D. Guo and S. Nagase, Org. Biomol. Chem., 2011, 9, 1731-1735; (c) S. Furukawa, J. Kobayashi and T. Kawashima, Dalton Trans., 2010, 39, 9329-9336; (d) M. Saito, T. Tanikawa, T. Tajima, J. D. Guo and S. Nagase, Tetrahedron Lett., 2010, 51, 672-675.

4 Q. Tan, S. Higashibayashi, S. Karanjit and H. Sakurai, Nat. Commun., 2012, 3, 891.

5 (a) Y.-T. Wu and J. S. Siegel, Chem. Rev., 2006, 106, 48434867; (b) V. M. Tsefrikas and L. T. Scott, Chem. Rev., 2006, 106, 4868-4884.

6 (a) H. Sakurai, T. Daiko, H. Sakane, T. Amaya and T. Hirao, J. Am. Chem. Soc., 2005, 127, 11580-11581; (b) S. Mebs,
M. Weber, P. Luger, B. M. Schmidt, H. Sakurai, S. Higashibayashi, S. Onogi and D. Lentz, Org. Biomol. Chem., 2012, 10, 2218-2222.

7 T. Amaya, H. Sakane and T. Hirao, Angew. Chem., Int. Ed., 2007, 46, 8376-8379.

8 H. Sakane, T. Amaya, T. Moriuchi and T. Hirao, Angew. Chem., Int. Ed., 2009, 48, 1640-1643.

9 T. Amaya, W.-Z. Wang, H. Sakane, T. Moriuchi and T. Hirao, Angew. Chem., Int. Ed., 2010, 49, 403-406.

10 B. Topolinski, B. M. Schmidt, M. Kathan, S. I. Troyanov and D. Lentz, Chem. Commun., 2012, 48, 6298-6300.

11 (a) J. C. Hanson and C. E. Nordman, Acta Crystallogr., Sect. B: Struct. Crystallogr. Cryst. Chem., 1976, 32, 1147-1153; (b) S. Grabowsky, M. Weber, Y.-S. Chen, D. Lentz, B. M. Schmidt, M. Hesse and P. Luger, Z. Naturforsch., B: J. Chem. Sci., 2010, 65, 452-460; (c) M. A. Petrukhina, K. W. Andreini, J. Mack and L. T. Scott, J. Org. Chem., 2005, 70, 5713-5716.

12 M. Yamada, S. Tashiro, R. Miyake and M. Shionoya, Dalton Trans., 2013, 42, 3300-3303.

13 (a) B. B. Shrestha, S. Karanjit, G. Panda, S. Higashibayashi and H. Sakurai, Chem. Lett., 2013, 386-388; (b) F. Mo, J. M. Yan, D. Qiu, F. Li, Y. Zhang and J. Wang, Angew. Chem., Int. Ed., 2010, 49, 2028-2032.

14 C. F. Macrae, I. J. Bruno, J. A. Chisholm, P. R. Edgington, P. McCabe, E. Pidcock, L. Rodriguez-Monge, R. Taylor, J. van de Streek and P. A. Wood, J. Appl. Crystallogr., 2013, 41, 466-470.

15 Persistence of Vision Pty. Ltd. http://povray.org/

16 (a) M. Nishio, CrystEngComm, 2004, 6, 130-158; (b) M. Nishio, Y. Umezawa, K. Honda, S. Tsuboyama and H. Suezawa, CrystEngComm, 2009, 11, 1757-1788.

17 (a) D. Vijay, H. Sakurai and G. N. Sastry, Int. J. Quantum Chem., 2011, 111, 1893-1901; (b) P. A. Denis, Chem. Phys. Lett., 2011, 516, 82-87.

18 D. Eisenberg, A. S. Filatov, E. A. Jackson, M. Rabinovitz, M. A. Petrukhina, L. T. Scott and R. Shenhar, J. Org. Chem., 2008, 73, 6073-6078.

19 SHELX - G. M. Sheldrick, Acta Crystallogr., Sect. A: Fundam. Crystallogr., 2008, 64, 112-122. 